\title{
Development of a model for mass production of Neoseiulus longispinosus, a phytoseiid predator of spider mites
}

\author{
G.G. Jayasinghe ${ }^{1^{*}}$ and B. Mallik ${ }^{2}$
}

\begin{abstract}
The two spotted spider mite (Tetranychus urticae Koch.) is a serious pest in greenhouses as well as on field grown crops. The predatory mites are important in regulating spider mite populations and should be conserved whenever possible due to their great predatory potential. The pyhtoseiid predator Neoseiulus (Amblyseius) longispinosus (Evans) has a wide distribution and has the ability to adapt to warm temperature inside poly houses under South Indian conditions. This study was undertaken to develop an efficient mass multiplication model for $\mathrm{N}$. longispinosus. To determine the highest yield of predatory mite N. lonigispinosus, both the prey ( $T$. urticae; 5 and 10 per leaflet) and predator mites ( 2 and 4 per leaflet) were released at two different ratio on French bean (FB) plants at four different growth stages as a tri trophic system. The treatments were imposed with three replicates in a factorial arrangement. Prey mites were released at 20, 25, 30 and 35 days after sowing (DAS) and predatory mites were released 10 days after prey mite release. The number of eggs, immature stages and adults of spider mites as well as predatory mites in each sample was recorded from 35 DAS. Two models where ten spider mites were released per leaflet on 20 DAS with 2 and 4 predatory mites released at 30 DAS, and the third model where release of spider mites at 25 DAS with two predators per leaflet were released, gave the highest yields of the predator. The first model was the most suitable, where the predators harvested was 1,087,130 (55 DAS), 1,362,600 (60 DAS) and 2,000,700 (65 DAS) per 300 pots, at a cost of production of Indian Rupees (INR) 7.5, 6.4 and 4.63 for 1000 predators, respectively. When four predators were used in the above model, 146,230, $325,840,700,110$ and 1,083,700 predators were harvested per 300 pots in 35, 40, 45 and 50 DAS, respectively. The costs of the 1000 predators were INR 40.39, 19.85, 10.04 and 7 , respectively. The present models were based on two repeated cycles (two times) and the information generated may be insufficient to draw a solid conclusion. Hence, these models need to be tested thoroughly to stabilize predator production.
\end{abstract}

Keywords: Mass multiplication model, Neoseiulus longispinosus, Tetranychus urticae

\section{Introduction}

The two spotted spider mite (Tetranychus urticae Koch.) has developed resistance to most of the acaricides after prolonged use and most of the pesticides are not effective on eggs. Predators are important in regulating spider mite populations and should be protected whenever possible due to their

\footnotetext{
${ }^{1}$ National Cinnamon Research \& Training Center, Dept. of Export Agriculture, Thihagoda, Sri Lanka

${ }^{2}$ University of Agricultural Sciences, GKVK, Bangalore, India

*Corresponding Author: ggjaya2005@yahoo.co.in
} 
higher predatory potential. Important predatory mite genera include Amblyseius, Neoseiulus, Typhlodromus, Metaseiulus and Phytoseiulus. The P. persimilis (Athias-Henriot) is the most common predator and it preys on all stages of mites (Osborn et al., 1999) and the pyhtoseiid predator, $N$. (Amblyseius) longispinosus (Evans) has a wide distribution with the ability to adapt to warm temperature inside poly houses under South Indian conditions (Mallik et al., 1998). The mass-rearing of predatory mites is a complex matter as it requires the maintenance of stable tri-trophic systems comprising of the predators, their prey and the host plants of the prey. Hoy et al. (1982) explained a method for large scale rearing of Typhlodromus occidentalis (Nesbitt), a predator, on T. urticae in a $45 \mathrm{~m}^{2}$ green house and estimated the optimum prey: predator ratio that should be maintained as 20-40:1. Mallik et al. (1999) harvested 4715 predators of $A$. longispinosus from 15 French bean plants and the cost of production of a single predator in the glass house was Indian Rupees 0.02. Kongchuensin et al. (2006) reported that Mung bean and cowpea should be more suitable as the host for mass-rearing of $T$. truncatus than soybean. This study was undertaken to develop efficient large scale mass multiplication model for $\mathrm{N}$. longispinosus at minimum cost and determine the most suitable combination of prey, T. urticae and predator mites, suitable growth stage on French bean plants and time taken to harvest the maximum yield of predators in a tri trophic system.

\section{Materials and Methods}

The study was conducted in a polycarbonate house of the Acarology Division, University of Agricultural Sciences, Bangalore, India. French bean (FB; Phaseolus vulgaris L.) plants of variety selection 9 were used for the study. The bean seeds were sown in $22 \mathrm{~cm}$ diameter earthen pots. The potting media was prepared with red soil and farm yard manure (FYM) and in each pot, four seedlings were raised, but later two were removed. Trichoderma (antagonistic fungus) culture was added to pots two times, namely two and four weeks after planting, to manage pathogenic fungi while chemical fertilizers (3 g of diammonium phosphate and $2 \mathrm{~g}$ of muriate of potash per pot) were added three weeks after sowing. The soil moisture level was maintained at field capacity using a drip irrigation system and temperature within the polycarbonate house was maintained below $35{ }^{\circ} \mathrm{C}$ using a blower-wet pad system especially during day time. The pots (288 in total), each containing two FB plants were used for the study.

To determine the highest yield of predatory mite N. longispinosus, both the prey $\mathrm{T}$. urticae ( 5 and 10 per leaflet or 50 and 100 per plant) and predator mites ( 2 and 4 per leaflet or 20 and 40 per plant), were released at two different ratios on French bean (FB) plants at four different growth stages as a tri trophic system. The treatments were imposed with three replications in factorial 
design. Six potted FB plants, two plants in each pot, were used for each treatment, 288 pots were arranged in groups of six, in the polycarbonate house, and treatments were imposed randomly. 20, 25, 30 and 35 days after sowing, ten leaflet of FB plants were sampled and the number of eggs, immature stages and adults of spider mites as well as predatory mites in each samples was recorded. During the observation, populations were computed for the total number of leaves in each plant. Densities of different life stages (eggs, immature and adults) were investigated with the Analysis of Variance (SAS Institute, 1989). The maximum harvestable population of predators in each combination of treatments, time taken to reach the maximum production and the cost of production were calculated. Thus, a protocol was developed for predatory mite production.

\section{Results and Discussion}

This study was planned to standardize the large scale mass rearing parameters and to estimate the cost of production of predators. Due to the maintenance of a stable tri-trophic system comprising of predators and their prey on the host plants, growth pattern of FB was observed initially. This plant has an ability to produce sufficient leaf biomass up to 60-70 days for rearing T. urticae. Threetrifoliate leaves (TLS) stage of FB was reached 20 DAS as this study was conducted in November-January (Figure 1).

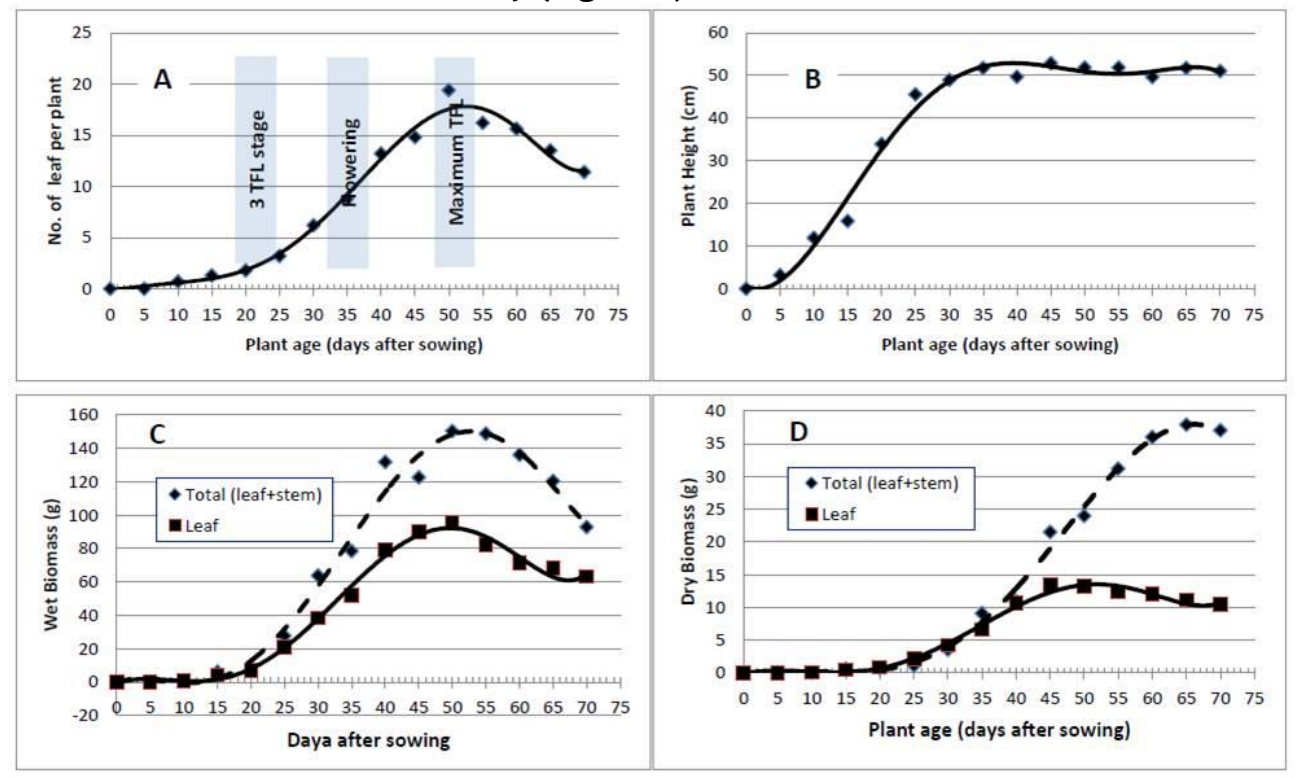

Figure 1. Growth parameters of French bean plants at different plant age: Number of trifoliate leaves (TFL) per plant (A), plant height (B), leaf and plant wet biomass per plant (C) and leaf and plant dry biomass per plant(D) 
If grown during summer, the three-trifoliate leaf stage of the crop could have been reached earlier. Vaidya (1999) reported that bean plants reached the trifoliate stage 12 days after sowing. Growth pattern of prey mites, T. urticae on FB was studied before the establishment of a tri trophic system for mass rearing of predatory mites. The prey mite T. urticae was introduced at low densities i.e. 100 and 200 per plant, at early growth stages of the FB plant (20 or 25 DAS). The mite populations reached the peak at 30 or 25 days after release. The maximum number of mites $(25,110$ per plant) was observed on FB plants that were subjected to the introduction of 100 mites per plant at 20 DAS. This was followed by 21950 mites per plant on those where 100 mites were introduced 25 DAS. On plants where 200 mites were introduced at 20 and 25 DAS, the maximum mite number reached was 21,520 and 20800, respectively (Table 1).

Table 1. Maximum number of spider mites (total of all stages) produced on French bean plants when different numbers initially released and plant age at release

\begin{tabular}{|c|c|c|c|c|c|c|}
\hline \multicolumn{2}{|l|}{ Treatments } & \multicolumn{4}{|c|}{ Maximum no. of spider mites per plant } & \multirow[b]{2}{*}{$\begin{array}{l}\text { Days to } \\
\text { reach } \\
\text { maximum } \\
\text { population }\end{array}$} \\
\hline $\begin{array}{l}\text { Plant age } \\
\text { (DAS) at } \\
\text { the time } \\
\text { of release } \\
\text { of mites }\end{array}$ & $\begin{array}{l}\text { No. of } \\
\text { mites } \\
\text { released } \\
\text { per plant }\end{array}$ & Eggs & $\begin{array}{r}\text { Immature } \\
\text { stages }\end{array}$ & Adults & Total & \\
\hline \multirow{3}{*}{$20(A 1)$} & $100(\mathrm{M} 1)$ & 15160.0 & $5434 \cdot 3$ & 4510.0 & 25110.3 & 30 \\
\hline & $200(M 2)$ & 12795.0 & $4844 \cdot 3$ & 3880.7 & 21520.0 & 25 \\
\hline & $400\left(M_{3}\right)$ & 11165.0 & 4120.3 & 2380.7 & 17609.7 & 20 \\
\hline \multirow{3}{*}{$25(\mathrm{~A} 2)$} & $100(\mathrm{M} 1)$ & 12165.0 & 5050.2 & 4735.2 & 21950.4 & 30 \\
\hline & $200(M 2)$ & 11320.1 & 4785.5 & 4656.3 & 20800.9 & 25 \\
\hline & $400\left(M_{3}\right)$ & 11220.2 & 4360.5 & 3370.1 & 18950.8 & 20 \\
\hline \multirow{3}{*}{$30\left(A_{3}\right)$} & $100(\mathrm{M} 1)$ & 8775.0 & 3217.5 & 2632.5 & 14625.0 & 25 \\
\hline & $200(M 2)$ & 11892.0 & 4360.4 & 3567.6 & 19820.0 & 25 \\
\hline & $400\left(M_{3}\right)$ & 7704.0 & 2824.8 & 2311.2 & 12840.0 & 20 \\
\hline \multirow{3}{*}{$35(\mathrm{~A} 4)$} & 100 (M1) & 7360.2 & 3400.1 & 1540.3 & 12300.6 & 20 \\
\hline & $200(\mathrm{M} 2)$ & 8660.3 & 1560.2 & 4140.4 & 14360.9 & 15 \\
\hline & $400\left(M_{3}\right)$ & 6810.0 & 1650.1 & 2900.5 & 11369.6 & 15 \\
\hline \multirow{3}{*}{$40(\mathrm{~A} 5)$} & 100 (M1) & 3410.2 & 1250.1 & 1040.5 & 5700.8 & 20 \\
\hline & $200(M 2)$ & 5480.1 & 2040.3 & 1780.3 & 9300.7 & 20 \\
\hline & $400\left(M_{3}\right)$ & 7010.0 & 2500.2 & 2190.2 & 11700.4 & 20 \\
\hline \multirow{3}{*}{$45(A 6)$} & $100(\mathrm{M} 1)$ & 2200.1 & 890.1 & 760.6 & 3850.8 & 15 \\
\hline & $200(M 2)$ & 3650.2 & 1400.0 & 1020.1 & 6070.3 & 15 \\
\hline & $400\left(M_{3}\right)$ & 6010.4 & 2350.1 & 1615.2 & 9975.7 & 15 \\
\hline
\end{tabular}

Among the three models evaluated for mass production of predators the building up of the predator population was delayed, in the first model (introduction to two predators per leaflet). However, with a delay of 25 to 35 days, about 50 to 123 predators could be harvested per leaflet. When four 
predators per leaflet were introduced to the same system (second model), only 6.77 to 46.3 predators were harvested per leaflet of FB plants at 5 to 20 days later (Table 2).

Table 2. Mean number of predatory mites per leaflet of FB in different treatments

\begin{tabular}{llllllllll}
\hline \multirow{2}{*}{ Treatments } & \multicolumn{6}{c}{ No. of predatory mites (all stages) per leaflet of FB, days after sowing } \\
\cline { 2 - 9 } & 30 & 35 & 40 & 45 & 50 & 55 & 60 & 65 & 70 \\
\hline $\mathrm{T} 1 S 1 P^{*}{ }^{*}$ & 2 & $1.03^{\mathrm{c}}$ & $3.5^{\mathrm{bcd}}$ & $8.87^{\mathrm{c}}$ & $16.6^{\mathrm{fg}}$ & $38.07^{\mathrm{abc}}$ & $48.05^{\mathrm{c}}$ & $36.10^{\mathrm{cd}}$ & $0.4^{\mathrm{b}}$ \\
$\mathrm{T} 1 \mathrm{~S} 1 \mathrm{P} 2$ & 4 & $3.00^{\mathrm{b}}$ & $7.13^{\mathrm{b}}$ & $16.27^{\mathrm{b}}$ & $26.93^{\mathrm{c}}$ & $39.40^{\mathrm{abc}}$ & $27.10^{\mathrm{d}}$ & $16.60^{\mathrm{cd}}$ & $0.1^{\mathrm{b}}$ \\
$\mathrm{T} 1 \mathrm{~S} 2 \mathrm{P} 1$ & 2 & $1.47^{\mathrm{c}}$ & $7.07^{\mathrm{b}}$ & $16.27^{\mathrm{b}}$ & $32.43^{\mathrm{b}}$ & $50.33^{\mathrm{a}}$ & $75.70^{\mathrm{a}}$ & $123.50^{\mathrm{a}}$ & $2.1^{\mathrm{b}}$ \\
$\mathrm{T} 1 \mathrm{~S} 2 \mathrm{P} 2$ & 4 & $6.77^{\mathrm{a}}$ & $12.9^{\mathrm{a}}$ & $25.93^{\mathrm{a}}$ & $46.3^{\mathrm{a}}$ & $28.00^{\mathrm{bcd}}$ & $14.00^{\text {ef }}$ & $2.80^{\mathrm{e}}$ & $0.1^{\mathrm{b}}$ \\
\hline $\mathrm{T} 2 \mathrm{~S} 1 \mathrm{P} 1$ & & 2 & $1.10^{\mathrm{d}}$ & $3.37^{\mathrm{e}}$ & $5.73^{\mathrm{i}}$ & $16.80^{\mathrm{de}}$ & $31.93^{\mathrm{d}}$ & $22.20^{\mathrm{cde}}$ & $0.1^{\mathrm{b}}$ \\
$\mathrm{T} 2 \mathrm{~S} 1 \mathrm{P} 2$ & & 4 & $1.80^{\mathrm{bc}}$ & $14.17^{\mathrm{b}}$ & $24.9^{\mathrm{cd}}$ & $8.40^{\mathrm{e}}$ & $2.27^{\mathrm{g}}$ & $1.90^{\mathrm{e}}$ & $0.1^{\mathrm{b}}$ \\
$\mathrm{T} 2 \mathrm{~S} 2 \mathrm{P} 1$ & & 2 & $2.80^{\mathrm{cd}}$ & $4.78^{\mathrm{de}}$ & $12.6^{\mathrm{gh}}$ & $27.0^{\mathrm{bcde}}$ & $48.00^{\mathrm{c}}$ & $88.00^{\mathrm{b}}$ & $16^{\mathrm{a}}$ \\
$\mathrm{T} 2 \mathrm{~S} 2 \mathrm{P} 2$ & & 4 & $7.00^{\mathrm{b}}$ & $17.00^{\mathrm{b}}$ & $32.00^{\mathrm{b}}$ & $55.00^{\mathrm{a}}$ & $17.50^{\mathrm{e}}$ & $4.10^{\mathrm{de}}$ & $0.1^{\mathrm{b}}$ \\
\hline Probability & -- & 0.001 & 0.005 & 0.001 & 0.001 & 0.005 & 0.001 & 0.001 & 0.01 \\
$\mathrm{SEM}{ }^{*}$ & -- & 0.42 & 4.88 & 5.15 & 8.09 & 136.7 & 26.2 & 377.6 & 17.5 \\
LSD & -- & 1.30 & 3.87 & 3.84 & 4.74 & 19.49 & 8.54 & 32.41 & 6.98 \\
$\mathrm{CV}$ & -- & 21.2 & 36.7 & 20.7 & 14.1 & 39.1 & 17.9 & 73.6 & 32.6 \\
\hline
\end{tabular}

Within a column, means followed by the same letter are not significantly different at $\mathrm{p}=0.05)$ * [ T: Age of the plants (days) when spider mites were released; $1-20,2-25$; $\mathrm{S}$ : Number of spider mites released per leaflet: 1- 5, 2-10; P: Number of predators released per leaflet: 1-2, 2-4]. Some uneconomical treatment combinations were removed from the Table 2. SEM - standard error of the mean; LSD - least significant difference; CV coefficient of variability.

In the third model, where release of spider mites was delayed by 5 days (25 DAS) with the introduction of two predators per leaflet, 88 predators could be harvested per leaflet at 25 days after their release. This indicates that if the number of predators released initially is just two, as the predator pressure will be low, the prey would built-up faster initially, resulting in more resources available to the predators though there is a delay. Hence the number of predators that can be harvested doubled with a delay of 15 days. When the number of predators produced over a period of one year is considered, the model with two predators per leaflet produced 11.22 million predators per 600 plants where only 7.884 million predators were produced in the model that introduced four predators per FB leaflet.

In economic terms, the predator $\mathrm{N}$. longispinosus can be produced in a large scale on FB plants in polycarbonate houses at low cost. The first model was the most suitable, where the predators harvested were 1,087,130 at 55 DAS, $1,362,600$ at 60 DAS and 2,000,700 at 65 DAS per 300 pots, at a cost of production of INR 7.5, 6.4 and 4.63 for 1000 predators, respectively. When four predators were used in the above model, 146,230, 325,840, 700,110 and $1,083,700$ predators were harvested per 300 pots at 35, 40, 45 and 50 DAS, 
respectively. The costs of the 1000 predators were INR 40.39, 19.85, 10.04 and 7, respectively. Cost of production of predators was comparatively higher in the second model as the predator yield was less. Higher predator densities reduced the prey population at the initial stage and finally, the predator yield itself was declined due to shortage of food (preys).

Vaidya (1999) and Mallik et al. (1999) studied the mass production of $A$. longispinosus on FB raised in pots in a glass house at a temperature of $40-41{ }^{\circ} \mathrm{C}$ and $30 \% \mathrm{RH}$. The cost of 100 predators inside the glass house was INR 20.00 and the present study showed that there is potential of further reduction of the cost of production of predators. The present models are based on two repeated cycles (two times) and the information generated may be insufficient to draw perfect conclusion, hence these models need to be tested thoroughly to stabilize predator production

For further development, the efficiency of natural enemies like phytoseiids needs be investigated under field conditions in different agroecological zones. Pesticide-resistant phytoseiids strains need to be developed as crops are normally grown under heavy pesticide umbrella. Sugeetha et al. (2007) has reported that $N$. longispinosus (Evans) has developed resistance to Monocrotophos and Dicofol by 55.89 and 23.59 folds, respectively, with continuous exposure to the chemicals for 40 generations. Farmer-friendly mass rearing methods need be developed, such as growing FB as an intercrop and using them for in situ production and use of predators.

\section{Acknowledgement}

Authors acknowledge the Council for Agriculture Research Policy (CARP), Sri Lanka for providing a grant facility for successful completion of this project in India as part of the post graduate degree programme.

\section{References}

Hoy, M.A., Castro, D. and Cahn, D. (1982): Two methods for large scale production of pesticide-resistant strains of the spider mite predator Metaseiulus occidentalis (Nesbitt) (Acarina, Phytoseiidae). Entomologie, 94: 1-9.

Kongchuensin, M., Charanasri, V. and takafuji, A. (2006): Suitable Host Plant and Optimum Initial Ratios of Predator and Prey for Mass-rearing the Predatory Mite, Neoseiulus longispinosus (Evans). J. Acarol. Soc. Japan. 15 (2): 145-150.

Mallik, B, Onkarappa, S. and Harish Kumar, M. (1998): Management of spider mites, Tetranuchus urticae Koch on rose using Phytoseiid predators, Amblyseius longispinosus (Evans) in polyhouses. Pest Mangt. Hort. Ecosyst. 4(1): 46-48.

Mallik, B., Vaidya, L.E. and Harish Kumar, N. (1999): Mass production of predators, Amblyseius longispinosus (Acari: Phytoseiidae) - model. J. Acarol. 15 (1 \& 2): 1517. 
Osborne, L.S., Ehiler, L.E. and Nechols, J.R. (1999): Biological control of the two spotted spider mites in greenhouses. http://www.mrec.ifas.edu/Iso/SpMite/b853al.htm (accessed on $30^{\text {th }}$ May 2008).

SAS Institute (1989): Version 6.12. SAS institute Inc., Cary NC.

Sugeetha, G., Mallik, B. and Sannaveerappanavar, V.T. (2007): Development of insecticide resistant strains of Neoseiulus longispinosus (Evans) (Acari: Phytoseiidae). J. Acarol., 17 (1\&2): 61 - 62.

Vaidya, R. (1999): Management of Tetranychus urticae Koch (Acari: Tetranychidae) on rose in poly house conditions using Amblyseius longispinosus (Evans) (Acari: Phytoseiidae). M.Sc. Thesis, Department of Entomology, University of Agricultural Sciences, Bangalore, pp 76. 
Jayasinghe and Mallik 